\title{
Small intestinal Crohn's disease with hepatic portal venous gas: a case report
}

\author{
Masato Yamadera ${ }^{1 *}$, Yoshiki Kajiwara', Eiji Shinto', Ryota Hokari², Hideyuki Shimazaki ${ }^{3}$, Junji Yamamoto', \\ Kazuo Hase ${ }^{1}$ and Hideki Ueno ${ }^{1}$
}

\begin{abstract}
An 80-year-old man presented in another hospital with acute abdominal pain; computed tomography indicated hepatic portal venous gas (HPVG) and small intestinal thickening. He was then transferred to our hospital, where we diagnosed idiopathic inflammation and stenosis of the ileum. Because the patient's abdominal symptoms were mild and his general condition was good, we chose to administer conservative therapy. His condition improved and we discharged him from our hospital. However, he was hospitalized again 9 days later because his abdominal pain had recurred and was worse. We performed a laparoscopic partial resection of the ileum 3 weeks after the patients' initial presentation. Macroscopically, longitudinal ulcers were observed near the stenosis of the ileum; the segment of the small intestine that contained the ulcers was removed, and subsequent pathological findings indicated Crohn's disease of the small intestine. The post-operative course was favorable, and the patient was discharged on post-operative day 9. Such serendipitous diagnosis of small intestinal Crohn's disease in an elderly patient with hepatic portal venous gas is rare; to our knowledge, this is the first of such case in which laparoscopic surgery was performed.
\end{abstract}

Keywords: Hepatic portal venous gas, Crohn's disease, Laparoscopic surgery

\section{Background}

Hepatic portal venous gas (HPVG) can occur alongside various gastrointestinal diseases and is often associated with a severe clinical course [1]. Recently, laparoscopic surgery for Crohn's disease (CD) is increasing, and it has been shown to be a safe and practical approach in selected patients [2]. However, the report of laparoscopic surgery for CD with HPVG was not found so far as we searched. Additionally, the peak age of $\mathrm{CD}$ onset occurs from 15-20 years, and elderly onset is rare [3]. Herein, we describe the case of an 80-year-old man with small intestinal CD who developed small intestinal obstruction with HPVG and who underwent laparoscopic surgical treatment.

\section{Case presentation}

An 80-year-old-man presented in another hospital with abdominal pain and nausea; he was transferred to our hospital for further examination and treatment, after

\footnotetext{
* Correspondence: masatoyamadera@yahoo.co.jp

'Department of Surgery, National Defense Medical College, Tokorozawa,

Saitama 359-8513, Japan

Full list of author information is available at the end of the article
}

HPVG was detected by enhanced abdominal computed tomography $(\mathrm{CT})$. With regard to the patient's medical history, he had previously undergone appendectomy, had been treated for pulmonary tuberculosis in the remote past, and had suffered tuberculous cervical lymphadenitis at the age of 76 years. His familial history was unremarkable. CT revealed marked HPVG, wall thickening in a part of the small intestine, and minor ascites in the pelvic space. At first admission, his body temperature was $38.8{ }^{\circ} \mathrm{C}$, blood pressure was $138 / 84 \mathrm{mmHg}$, and pulse rate was 109 beats per minute (bpm). Physical examination revealed slight abdominal distention with mild tenderness of the lower abdomen; however, no signs of peritoneal irritation were found. As the patient was in good general health, we chose to treat him using conservative therapy. The next day, no HPVG was identified upon CT scanning, and his abdominal pain had diminished. He restarted oral feeding at that point, and was discharged on the tenth hospital day. We planned to follow him up as an outpatient; however, he was hospitalized again 9 days after discharge because his abdominal pain had recurred and was worse.

At readmission, his body temperature was $37.3^{\circ} \mathrm{C}$, blood pressure was $90 / 56 \mathrm{mmHg}$, and pulse rate was $92 \mathrm{bpm}$. He 


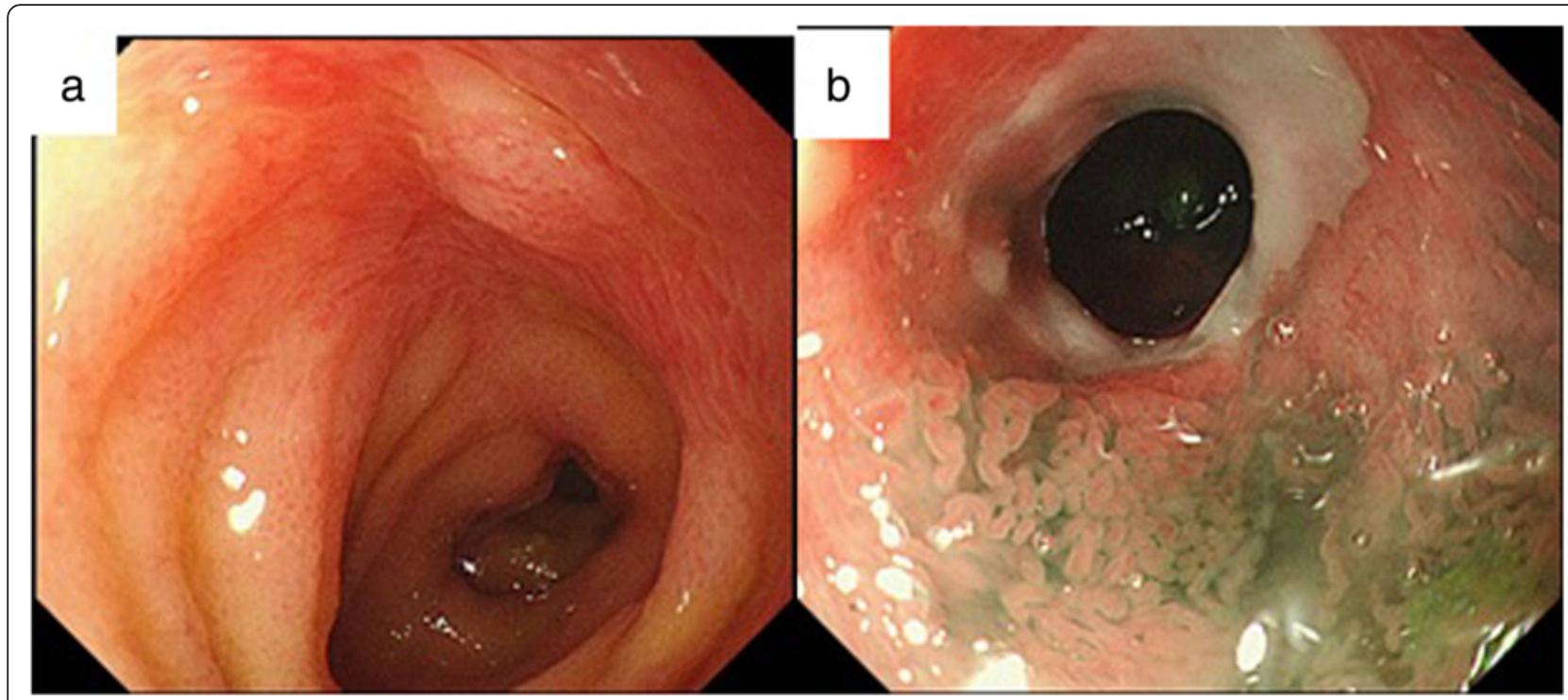

Fig. 1 Fiber colonoscopy showing a linear ulcer (a) and a circular ulcer (b) in the ileum, $40 \mathrm{~cm}$ from the ileum end

showed slight abdominal distention and rebound tenderness of the lower abdomen, but no signs of abdominal guarding. Concerning laboratory findings, his white blood cell count was $16,800 / \mu \mathrm{l}$, with $91.6 \%$ neutrophils; he had a C-reactive protein level of $1.5 \mathrm{mg} / \mathrm{dl}$. Acid-fast bacterial testing of gastric juice and sputum was negative, as was the QuantiFERON $^{\mathrm{m}}$ TB-2G test for tuberculosis. Plain radiographs of the abdomen showed the note gas in the small intestine, and colonoscopic examination revealed a linear and a circular ulcer in the ileum approximately $40 \mathrm{~cm}$ orally from the Bauchin valve; a stricture prevented further passage of the scope (Fig. 1a, b). Gastrografin examination of the small intestine showed constriction of the terminal ileum (Fig. 2a, b), while the jejunum was normal. Enhanced abdominal CT at readmission revealed that the HPVG (Fig. 3a, b) had not recurred (Fig. 3c); however, the thickening of the ileum wall, the edematous change, and the minor ascites in the pelvic space had not improved (Fig. 3d). No intraperitoneal air was found.

We presumptively diagnosed idiopathic partial ileitis with stenosis; prompted by the unresponsiveness to conservative therapy, we performed surgery. Upon laparoscopy, we found minor serous ascites and wall stiffness at the $20-\mathrm{cm}$ segment of the mid-to-distal ileum. A $25-\mathrm{cm}$ segment of the small intestine that included the disease was resected laparoscopically (Fig. 4). There were no adhesions throughout the peritoneal space, and the other parts of bowel were normal. The resected specimen had a thickened small intestinal wall. Linear ulcers were found approximately $5 \mathrm{~cm}$ on either side of the stricture, which was located at the mesentery side of small intestine. The dissection margin was free of ulceration. Pneumatosis cystoides intestinalis was not found (Fig. 5). Pathological examination revealed
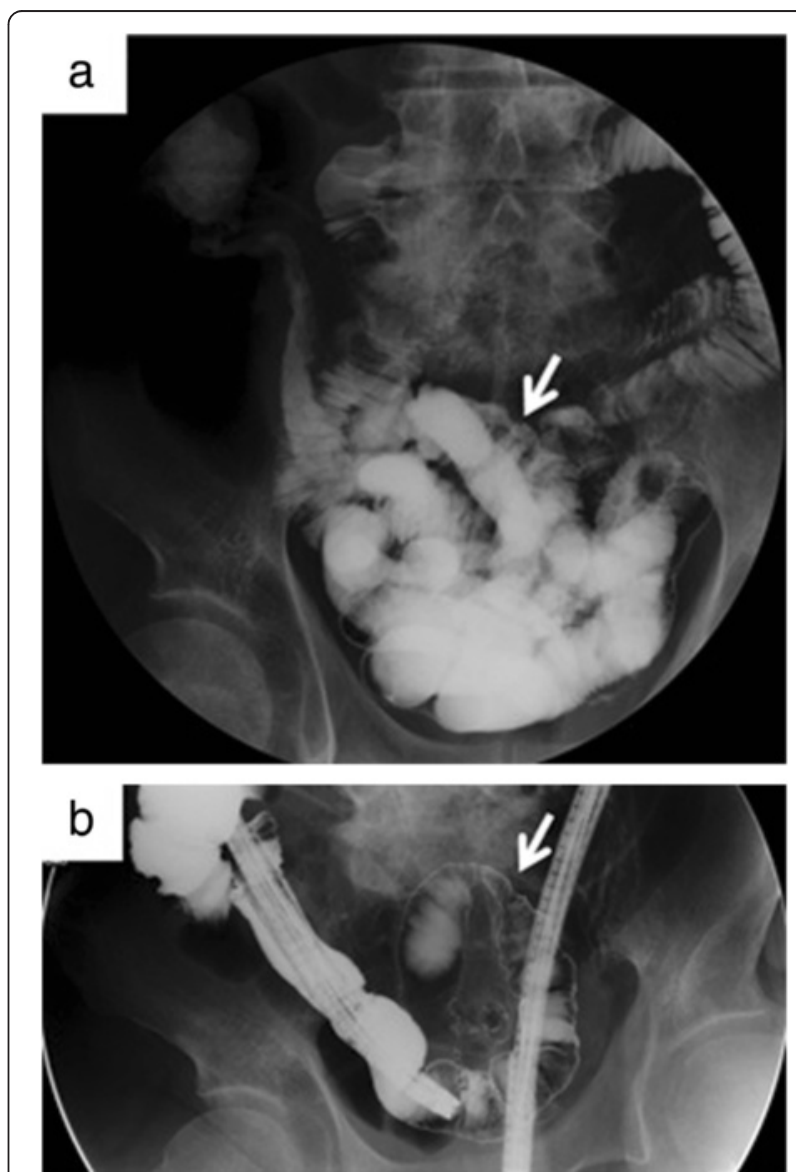

Fig. 2 Enema examination showing the stenosis at the small intestine near the terminal ileum (a, b; arrow) 

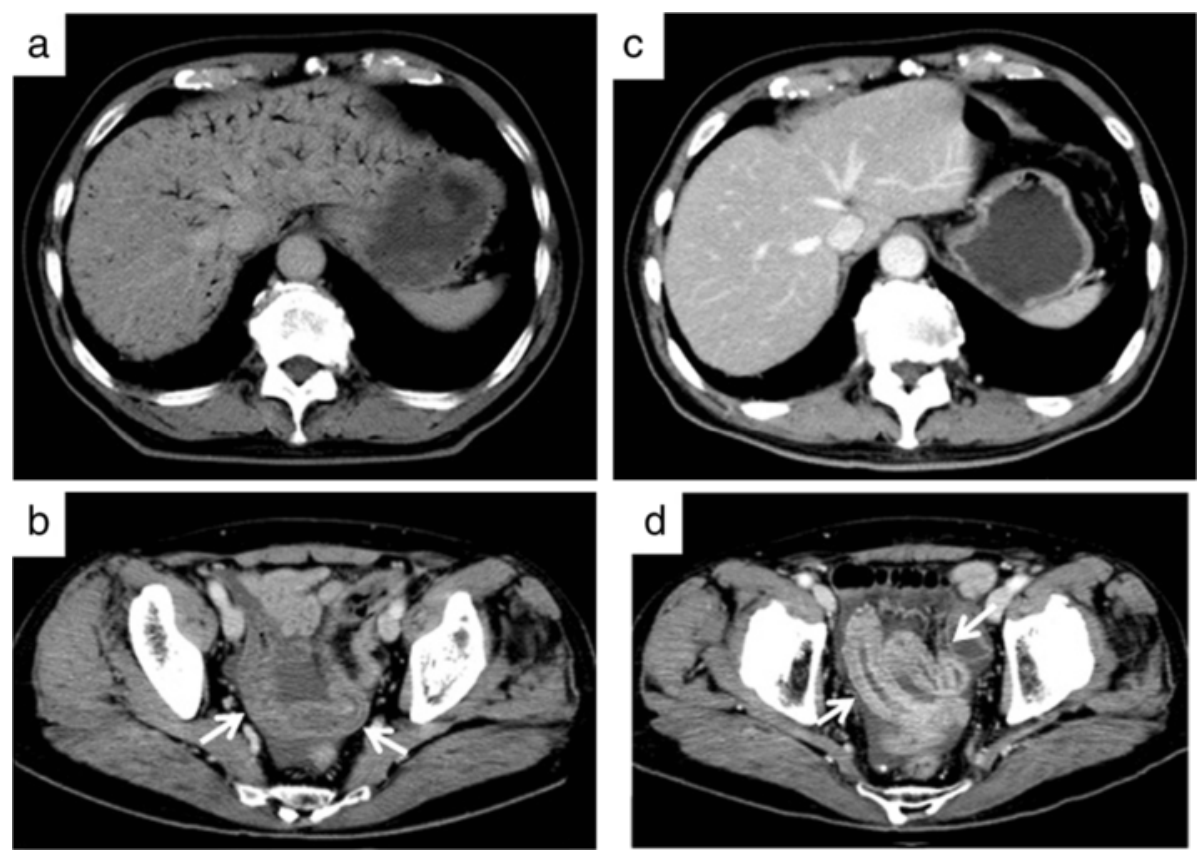

Fig. 3 Contrast-enhanced abdominal computed tomography showing hepatic portal venous gas (HPVG) (a) and thickening of the ileum wall (b; arrow). Upon readmission to our hospital, the HPVG disappeared (c) but the ileum wall thickening did not improve (d; arrow)

that the submucosal layer alongside the linear ulcer contained epithelioid cell granuloma. Furthermore, inflammation spanned the entire depth of the intestinal wall, with focal infiltration of neutrophils, lymphocytes, and plasma cells; this strongly indicated CD (Fig. 6). After surgery, the patient had an uneventful recovery and was discharged on post-operative day 9 . He has continued to do very well following his discharge. Follow-up gastroscopy and colonoscopy have revealed no CD-like lesions in any other part of the gastrointestinal tract, from the esophagus to the anus.

\section{Discussion}

HPVG is characterized by linear or dendric radiolucencies along the periphery of the liver on CT images. This is in

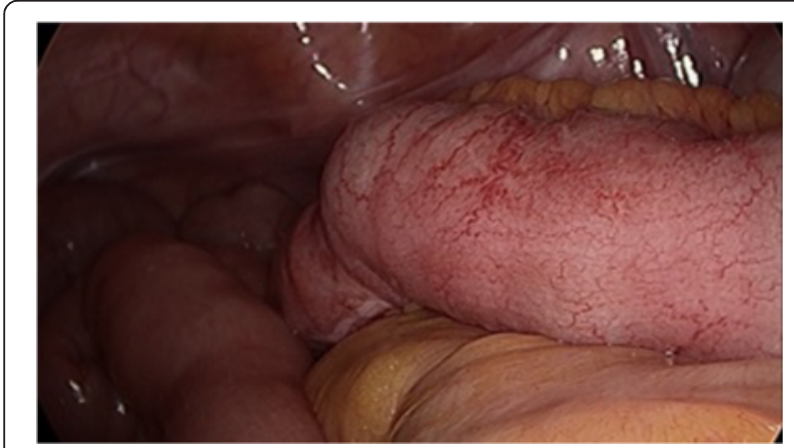

Fig. 4 Operative findings showing inflammatory thickening of the small intestine 30 to $50 \mathrm{~cm}$ from the terminal ileum contrast to biliary air, which is central and almost never extends to the periphery. Gas in the portal venous system is likely transported to small peripheral branches in the liver as a result of the centrifugal flow of the portal venous blood [4]. With regard to the mechanism of HPVG, it has been suggested that elevated intraluminal pressure caused by constriction of the intestine can allow bowel gas to enter the portal venous circulation through either microscopic mucosal perforations or disease invasions deeper than the submucosal layer [1]. HPVG has been reported in various abdominal diseases, namely, gastric ulcer, inflammatory bowel disease, bowel ischemia, acute enteritis, and simple bowel obstruction. Occasionally, the symptom

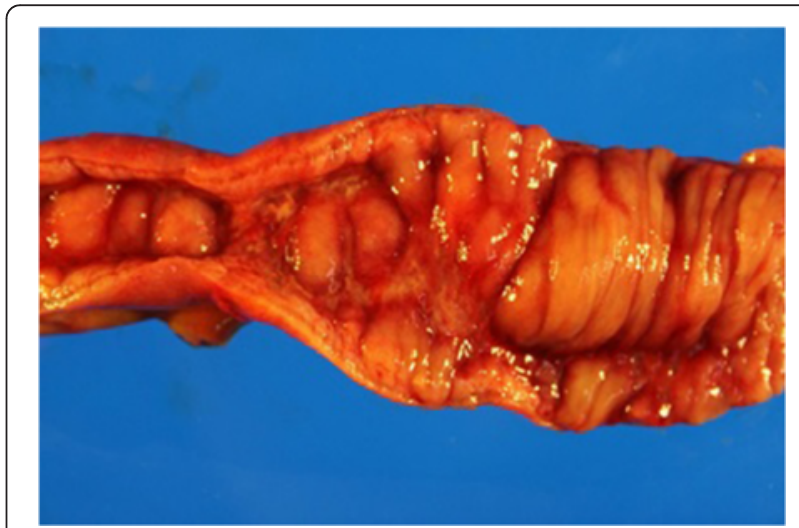

Fig. 5 Macroscopic appearance of the resected specimen. The intestine wall was remarkably thickened. Linear ulcer and stenosis were observed 


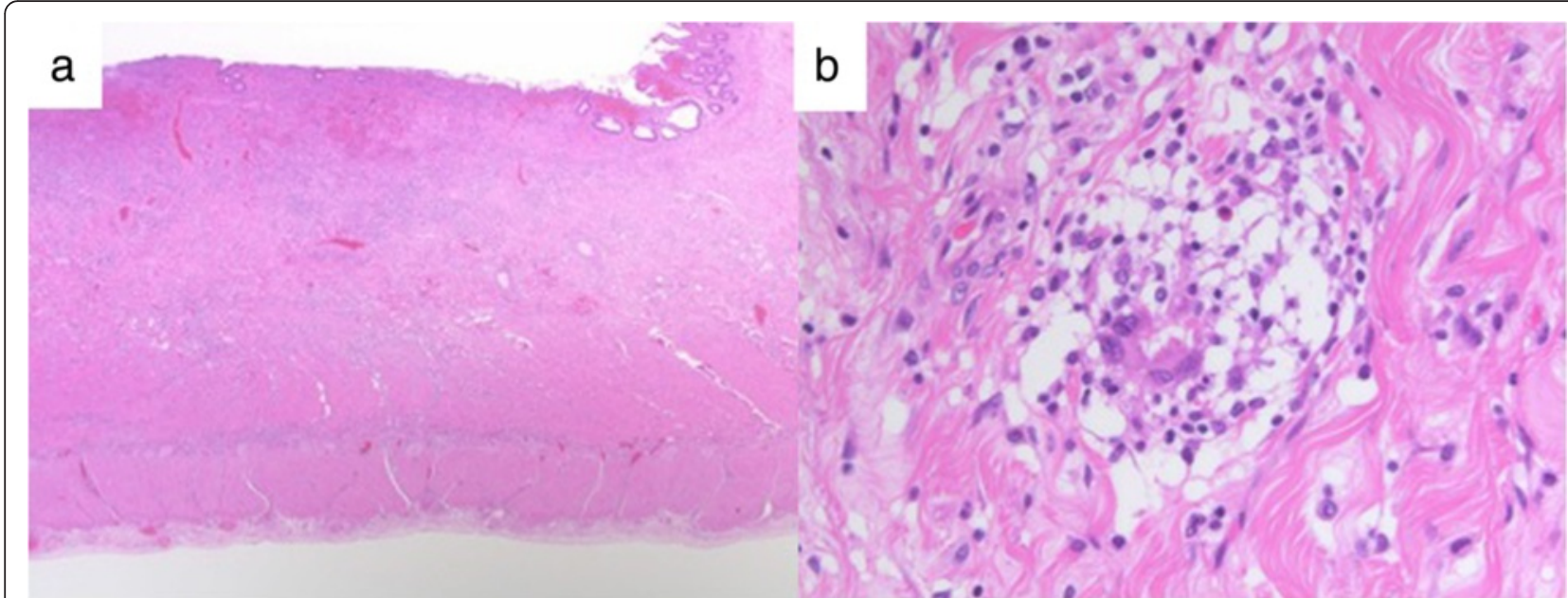

Fig. 6 Histopathological analysis showing inflammatory cell invasion through all layers of the intestine $(\mathbf{a}$; hematoxylin and eosin stain $\times 5)$ and epithelioid granulomas (b; hematoxylin and eosin stain, object lens $\times 40$ )

Table 1 Reported cases of Crohn's disease (CD) with HPVG

\begin{tabular}{|c|c|c|c|c|c|c|c|c|}
\hline No. & Author & Year & Age & Sex & Symptoms & $\begin{array}{l}\text { Duration between } \\
\text { onset of } C D \text { and HPVG }\end{array}$ & Operation & Outcome \\
\hline 1 & Pappas et al. [12] & 1984 & 36 & M & $\begin{array}{l}\text { Left-sided lower abdominal } \\
\text { pain, tenesmus, liquid stools }\end{array}$ & At onset & Conservative therapy & Alive \\
\hline 2 & Huycke et al. [13] & 1985 & 22 & M & Abdominal pain & 6 years & Ileocolic resection & Alive \\
\hline 3 & Kirsch et al. [14] & 1990 & 26 & $\mathrm{~F}$ & $\begin{array}{l}\text { Epigastric pain, chills, nausea, } \\
\text { vomiting }\end{array}$ & At onset & Conservative therapy & Alive \\
\hline 4 & Venugopal et al. [10] & 1990 & 27 & $\mathrm{~F}$ & Nausea, vomiting, fever & 5 years & $\begin{array}{l}\text { Partial resection of the } \\
\text { ileum }\end{array}$ & Alive \\
\hline 5 & Delamarre et al. [15] & 1991 & 70 & M & Abdominal pain, fever & 4 years & Conservative therapy & Alive \\
\hline 6 & al-Jahdali et al. [16] & 1994 & 40 & $\mathrm{~F}$ & Abdominal pain, nausea & 20 years & $\begin{array}{l}\text { Partial resection of the } \\
\text { ileum }\end{array}$ & $\begin{array}{l}\text { Not } \\
\text { described }\end{array}$ \\
\hline 7 & Brandon et al. [17] & 2000 & 59 & $\mathrm{~F}$ & $\begin{array}{l}\text { Nausea, vomiting, loose stool, } \\
\text { chills vague abdominal pain }\end{array}$ & At onset & Right hemicolectomy & $\begin{array}{l}\text { Not } \\
\text { described }\end{array}$ \\
\hline 8 & Thethy et al. [18] & 2005 & 58 & $\mathrm{~F}$ & $\begin{array}{l}\text { Malaise, rigors, bloody diarrhea, } \\
\text { vague perianal pain }\end{array}$ & Not described & Partial colectomy & Alive \\
\hline 9 & Salyers et al. [4] & 2007 & 24 & M & Abdominal pain, nausea & Not described & Conservative therapy & Alive \\
\hline 10 & Alqahtani et al. [19] & 2007 & 26 & $\mathrm{~F}$ & $\begin{array}{l}\text { Right-sided upper quadrant } \\
\text { abdominal pain }\end{array}$ & 3 years & Conservative therapy & Alive \\
\hline 11 & Hokama et al. [20] & 2009 & 44 & M & Severe abdominal pain, vomiting & 28 years & $\begin{array}{l}\text { Partial resection of small } \\
\text { intestine }\end{array}$ & Alive \\
\hline 12 & Lim et al. [9] & 2011 & 32 & M & $\begin{array}{l}\text { Lower abdominal pain, nausea, } \\
\text { vomiting, fever }\end{array}$ & 12 years & Ileocecal resection & Alive \\
\hline 13 & Ujihara et al. [21] & 2013 & 54 & $\mathrm{~F}$ & Abdominal pain, nausea & 36 years & Conservative therapy & Alive \\
\hline 14 & Rao et al. [22] & 2013 & 52 & $\mathrm{~F}$ & Abdominal pain, vomiting & 11 years & $\begin{array}{l}\text { Elective colonic } \\
\text { resection }\end{array}$ & Alive \\
\hline 15 & Pinto Pais et al. [23] & 2014 & 43 & $\mathrm{~F}$ & Abdominal pain, vomiting, fever & At onset & Conservative therapy & Alive \\
\hline 16 & Cunningham et al. [24] & 2014 & 27 & $\mathrm{~F}$ & $\begin{array}{l}\text { Fever, rigors, abdominal pain, } \\
\text { vomiting, diarrhea }\end{array}$ & Not described & Conservative therapy & Alive \\
\hline 17 & Our case & - & 80 & M & Nausea, abdominal pain & At onset & $\begin{array}{l}\text { Partial resection of the } \\
\text { ileum }\end{array}$ & Alive \\
\hline
\end{tabular}


is iatrogenic [5-7]. HPVG is a critical sign, with an associated mortality rate of 25 to $39 \%$ [6-8]. Therefore, the condition has been considered an indication for urgent surgical intervention, especially if the HPVG was caused by bowel necrosis, abscess, or massive damage to the mucosa of the alimentary canal [6]. Conversely, Lim et al. [9] suggested that treatment of patients with HPVG should be based on the underlying disease, as well as the patient's clinical condition. Moreover, Venugopal et al. [10] reported that HPVG does not necessarily indicate necrotic bowel in patients with $C D$; Kinoshita et al. [6] demonstrated that approximately $4 \%$ of HPVG cases occur alongside CD and that such cases almost always have a good clinical course. Our case corroborates this claim.

HPVG is likely to occur in the elderly $[6,11]$. In contrast, $\mathrm{CD}$ usually begins in young people-only around $5 \%$ of $\mathrm{CD}$ cases have an age of onset of 65 years or older [3]. For this reason, in the present case, we suspected intestinal tuberculosis, intestinal ischemia, or post-operative adhesive small bowel obstruction rather than inflammatory bowel disease, including CD. However, repeat examinations for tuberculosis were all negative, and some macroscopic findings indicated $\mathrm{CD}$ in the resected specimen. Ultimately, we diagnosed $\mathrm{CD}$ based on histopathological findings in the resected specimen.

CD with HPVG has been reported in the literature; we carried out a search of PubMed wherein we crossreferenced the terms "Crohn's disease" and "hepatic portal venous gas." We found 17 cases including our own (Table 1) [4, 9, 10, 12-24]. That is, new-onset small intestinal CD in an elderly patient presenting with HPVG is rare; to our knowledge, this case was the first for which laparoscopic surgery was performed. It has been suggested that laparoscopic intervention combined with treatment is useful in cases of bowel disease that lead to HPVG if (1) no peritoneal irritation signs are noted, and (2) the patient's physical condition is stable; these two criteria describe our case well. Moreover, partial resection of the intestine that contains the affected area is a valid, reliable therapy for HPVG in cases where it may lead to more serious disease.

\section{Conclusions}

We have reported the first case of small intestinal CD with HPVG treated laparoscopically.

\section{Consent}

Written informed consent was obtained from the patient for publication of this case report and any accompanying images. A copy of the written consent form is available for review by the Editor-in-Chief of this journal upon request.

\section{Abbreviations}

bpm, beats per minute; $C D$, Crohn's disease; $C$, computed tomography: HPVG, hepatic portal venous gas

\section{Competing interests}

The authors declare that they have no competing interests.

\section{Authors' contributions}

$\mathrm{MY}$ and $\mathrm{HU}$ carried out the surgery and post-operative management. MY drafted the manuscript and $\mathrm{YK}$ and $\mathrm{HU}$ critically revised the manuscript. $\mathrm{RH}$ carried out the medical diagnosis. HS carried out the pathological diagnosis. $E S, J Y, K H$, and HU participated in the study design and coordination and helped to draft the manuscript. All authors read and approved the final manuscript.

\section{Acknowledgements}

We thank all staffs, who were employed at National Defense Medical College, for treating and caring for this patient.

\section{Author details}

${ }^{1}$ Department of Surgery, National Defense Medical College, Tokorozawa, Saitama 359-8513, Japan. ${ }^{2}$ Department of Internal Medicine, National Defense Medical College, Tokorozawa, Saitama 359-8513, Japan. ${ }^{3}$ Department of Pathology and Laboratory Medicine, National Defense Medical College, Tokorozawa, Saitama 359-8513, Japan.

Received: 8 March 2016 Accepted: 21 June 2016

Published online: 28 June 2016

\section{References}

1. Liebman PR, Patten MT, Manny J, Benfield JR, Hechtman HB. Hepatic_-portal venous gas in adults: etiology, pathophysiology and clinical significance. Ann Surg. 1978;187(3):281-7.

2. Jennifer HM, Priscilla M, Stefan DH. Minimally invasive surgery for inflammatory bowel disease. Inflamm Bowel Dis. 2015;21(6):1443-58.

3. Asakura K, Nishiwaki Y, Inoue N, Hibi T, Watanabe M, Takebayashi T. Prevalence of ulcerative colitis and Crohn's disease in Japan. J Gastroenterol. 2009;44(7):659-65.

4. Salyers WJ, Mansour A. Portal venous gas following colonoscopy and small bowel follow-through in a patient with Crohn's disease. Endoscopy. 2007;39 Suppl 1, e130

5. Abboud B, El Hachem J, Yazbeck T, Doumit C. Hepatic portal venous gas: physiopathology, etiology, prognosis and treatment. World J Gastroenterol. 2009;15(29):3585-90.

6. Kinoshita H, Shinozaki M, Tanimura $\mathrm{H}$, et al. Clinical features and management of hepatic portal venous gas: four case reports and cumulative review of the literature. Arch Surg. 2001;136(12):1410-4

7. Iannitti DA, Gregg SC, Mayo-Smith WW, Tomolonis RJ, Cioffi WG, Pricolo VE. Portal venous gas detected by computed tomography: is surgery imperative? Dig Surg. 2003;20(4):306-15.

8. Faberman RS, Mayo-Smith WW. Outcome of 17 patients with portal venous gas detected by CT. AJR Am J Roentgenol. 1997;169(6):1535-8.

9. Lim JW, Kim KJ, Ye BD, et al. Enterovenous fistulization: a rare complication of Crohn's disease. World J Gastroenterol. 2011;17(47):5227-30.

10. Venugopal C, Colley DP. Portal venous gas in a patient with Crohn's disease. I Clin Gastroenterol. 1990;12(5):595-7.

11. Sadatomo A, Koinuma K, Kanamaru R, et al. Hepatic portal venous gas after endoscopy in a patient with anastomotic obstruction. World J Gastrointest Surg. 2015;7(2):21-4

12. Pappas D, Romeu J, Tarkin N, Dave PB, Messer J. Portal vein gas in a patient with Crohn's colitis. Am J Gastroenterol. 1984;79(9):728-30.

13. Huycke A, Moeller DD. Hepatic portal venous gas after colonoscopy in granulomatous colitis. Am J Gastroenterol. 1985;80(8):637-8.

14. Kirsch M, Bozdech J, Gardner DA. Hepatic portal venous gas: an unusual presentation of Crohn's disease. Am J Gastroenterol. 1990;85(11):1521-3.

15. Delamarre J, Capron JP, Dupas JL, Deschepper B, Jouet-Gondry C, Rudelli A. Spontaneous portal venous gas in a patient with Crohn's ileocolitis. Gastrointest Radiol. 1991;16(1):38-40.

16. Al-Jahdali H, Pon C, Thompson WG, Matzinger FR. Non-fatal portal pyaemia complicating Crohn's disease of the terminal ileum. Gut. 1994;35(4):560-1. 
17. Brandon T, Bogard B, ReMine S, Urban L. Early recognition of hepatic portal vein gas on $\mathrm{CT}$ with appropriate surgical intervention improves patient survival. Curr Surg. 2000;57(5):452-5.

18. Thethy SS, Potter MA. An unusual complication of Crohn's colitis. Gut. 2005; 54(6):768. 96.

19. Alqahtani S, Coffin CS, Burak K, Chen F, MacGregor J, Beck P. Hepatic portal venous gas: a report of two cases and a review of the epidemiology, pathogenesis, diagnosis and approach to management. Can J Gastroenterol. 2007;21(5):309-13.

20. Hokama A, Nagahama M, Kishimoto K, et al. Pneumatosis intestinalis and hepatic portal venous gas in Crohn's disease. J Crohns Colitis. 2009;3(4):313-4.

21. Ujihara $M$, Ando $T$, Ishiguro $K$, et al. Hepatic portal venous gas following colonoscopy in a patient with Crohn's disease. Nagoya J Med Sci. 2013;75(3-4):273-8.

22. Rao S, Tkacz JN, Farraye FA. Portal venous gas after colonoscopy in two patients with Crohn's disease. Gastrointest Endosc. 2013;77(2):316-8.

23. Pinto Pais T, Pinho R, Carvalho J. Hepatic portal venous gas and intestinal pneumatosis as initial presentation of Crohn's disease: first case report. J Crohns Colitis. 2014;8(10):1329-30.

24. Cunningham G, Cameron G, De Cruz P. Hepatic portal venous gas in Crohn's disease. BMJ Case Rep. 2014; doi: 10.1136/bcr-2014-206244.

\section{Submit your manuscript to a SpringerOpen ${ }^{\circ}$ journal and benefit from:}

- Convenient online submission

- Rigorous peer review

- Immediate publication on acceptance

- Open access: articles freely available online

High visibility within the field

- Retaining the copyright to your article

Submit your next manuscript at $\gg$ springeropen.com 